\begin{tabular}{|c|c|c|}
\hline & $\begin{array}{l}\text { JURNAL ILMIAH TEKNIK MESIN, INDUSTRI, } \\
\text { ELEKTRO DAN SIPIL }\end{array}$ & (9) \\
\hline VORTEKS & Halaman: 71-77 & \\
\hline
\end{tabular}

\title{
ANALISIS RESCHEDULE TERHADAP PELAKSANAAN PEKERJAAN STRUKTUR BAWAH GEDUNG FMIPA UNIMED
}

\author{
Muhammad Yusup ${ }^{1 *}$, \\ ${ }^{1}$ Program Studi Teknik Sipil, Fakultas Teknik Universitas Al Azhar Medan \\ Jl. Pintu Air IV No.214, Kwala Bekala, Medan, Sumatera Utara- 201422 \\ Email : muhammadyusuf@gmail.com
}

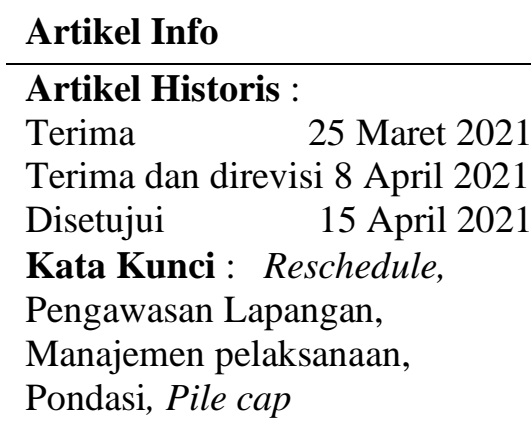

Keywords: Reschedule, Field Supervision, Implementation management, Foundation, Pile cap

\begin{abstract}
Abstrak
Dari hasil analisis urutan pelaksanaan diperoleh bahwa metode pelaksanaan pekerjaan pilecap dilakukan setelah pekerjaan pondasi selesai seratus persen. Hal ini menyebabkan adanya durasi waktu yang terbuang tanpa ada pelaksanaan yang bisa dilakukan, dengan menunggu pekerjaan pondasi selesai. Seharusnya ada pekerjaan yang dapat dilakukan secara bersamaan seperti pekerjaan pengeboran pondasi dan pengecoran sektor 2 dapat dilakukan bersama dengan pekerjaan pile cap disektor 1 . Metode kerja juga dibagi menjadi dua zona pelaksanaan yaitu sektor 1 dan sektor 2, dimana masing masing sektor dibagi dalam pekerjaan yang sama yaitu pengeboran pondasi sekaligus pengecoran pile dan pekerjaan pile cap. Pembagian kerja ini juga selain memudahkan pekerjaan, juga dapat mempercepat durasi pelaksanaan pekerjaan struktur bawah gedung tersebut. Persiapan kerja seperti pengukuran, pembebasan lokasi kerja, kesiapan material, mobilisasi alat berat, dan keandalan man power yang terdiri dari pekerja dan manajemen pengawasan menjadi pendukung kuat keefektifan pelaksanaan pekerjaan di lapangan. Struktur kerja dan kecakapan teknik lapangan yang terstruktur dengan baik akan memberikan analisis dan keputusan lapangan yang solutif juga sangat diharapkan sebagai komponen manajemen lapangan yang baik
\end{abstract} \footnotetext{
Abstract

From the results of the analysis of the sequence of implementation, it was found that the method of implementing the pilecap work was carried out after one hundred percent of the foundation work was completed. This results in a wasted duration of time without any work, waiting for the foundation work to be completed. Work that can be done simultaneously, such as foundation drilling work and casting sector two, can be done together with pile cap work in sector 1. The work method is also divided into two implementation zones, namely sector one and sector 2 , where each sector is divided into the same work namely foundation drilling as well as pile casting and pile cap work. Apart from facilitating the work, this division of labor can also speed up the duration of the implementation of the structural work under the building.

Work preparation such as measurement, work location release, material readiness, heavy equipment mobilization, and reliability of
} 


\title{
JURNAL ILMIAH TEKNIK MESIN, INDUSTRI, ELEKTRO DAN SIPIL
}

\author{
Halaman: 71-77
}

\begin{abstract}
man power consisting of workers and supervisory management are strong supporters of the effectiveness of the implementation of work in the field. A well-structured work structure and field engineering skills will provide a solution for analysis and field decisions that are also highly expected as a component of good field management.
\end{abstract}

\section{PENDAHULUAN}

Manajemen proyek merupakan suatu upaya dalam perencanaan, pengorganisasian, pengarahan dan pengendalian sumber daya pada suatu organisasi atau perusahaan untuk mencapai tujuan tertentu dalam waktu tertentu dengan sumber daya tertentu [1]. Tujuan utama manajemen proyek adalah agar semua rangkaian kegiatan tersebut tepat waktu, tepat biaya, dan kualitas serta proses sesuai dengan persyaratan. Untuk mencapai tujuan tersebut, perlu dilakukan pengawasan terhadap mutu, biaya, dan waktu. Oleh karena itu, dilakukan pelaksanaan pengawasan mutu (quality control), pengawasan biaya (cost control), dan pengawasan waktu pelaksanaan (time control). Ketiga pengawasan ini dilakukan secara bersamaan [2]. Jaringan kerja merupakan cara grafis untuk menggambarkan kegiatan kegiatan dan kejadian yang diperlukan untuk mencapai harapan-harapan proyek, dimana semua tahapan tersebut harus dilakukan dengan perencanaan bertahap dan saling mengikat jaringan antara satu tahapan pekerjaan dengan tahapan pekerjaan lain, atau disebut dengan Networking. Kegunaan network planning dalam manajemen proyek adalah dalam network planning ditunjukkan dengan jelas pekerjaan-pekerjaan yang waktunya penyelesaiannya kritis dan yang tidak, sehingga memungkinkan pengaturan pembagian usaha terhadap pekerjaan [3].

Pondasi Bore Pile adalah jenis pondasi dalam yang berbentuk tabung, yaitu berfungsi meneruskan beban struktur bangunan diatasnya dari permukaan tanah sampai lapisan tanah keras di bawahnya. Pondasi bore pile memiliki fungsi yang sama dengan pondasi tiang pancang atau pondasi dalam lainya. Perbedaan di antara keduanya adalah pada cara pelaksanaan pengerjaannya. diawali dari pembuatan lubang di tanah dengan cara tanah di bor terlebih dahulu kemudian penginstalan besi tulangan ke dalam lubang yang dilanjutkan dengan pengecoran bor pile dengan tremi.

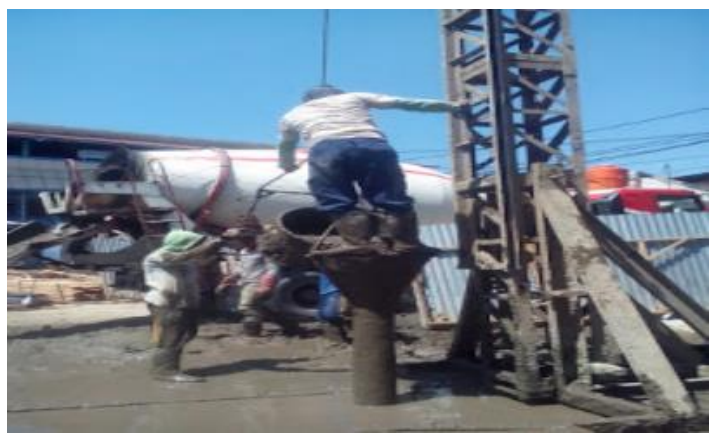

Gambar 1. Alat Cor Tremi

Pile cap merupakan tumpukan topi merupakan cara untuk mengikat pondasi sebelum mendirikan kolom dibab alas. Tumpukan topi tersusun atas tulangan baja berdiameter $16 \mathrm{~mm}, 19 \mathrm{~mm}$ dan $25 \mathrm{~mm}$ yang membentuk bidang dengan ketebalan $50 \mathrm{~mm}$, dan lebar yang berbeda - beda, tergantung dari jumlah tiang yang tertanam. Fungsi dari Pilecap yaitu untuk mendapatkan beban dari kolom yang lalu akan terus disebarkan ke tiang pancang dimana masing - masing pile mendapatkan 1/N dari beban oleh kolom dan harus < daya dukung yang diizinkan ( $\mathrm{Y}$ ton) $(\mathrm{N}=$ jumlah kelompok pile). Beban maximum yang sanggup diterima oleh pilecap dari suatu kolom yaitu sebesar N x (Y ton). Pilecap ini bertujuan agar lokasi kolom benar - benar tidak menyebabkan eksentrisitas yang sanggup menyebabkan beban lain - lain pada pondasi. Selain itu menyerupai halnya kepala kolom, pilecap juga berfungsi untuk menahan gaya geser dari pembebanan yang ada bentuk dari pilecap juga bervariasi dengan bentuk 


\section{JURNAL ILMIAH TEKNIK MESIN, INDUSTRI, ELEKTRO DAN SIPIL}

Analisis reschedule terhadap pelaksanaan pekerjaan struktur bawah gedung fmipa UNIMED

segitiga dan persegi panjang. Jumlah kolom yang diikat pada tiap pilecap pun berbeda tergantung kebutuhan atas beban yang akan diterimanya. Terdapat pilecap dengan pondasi tunggal, ada yang mengikat 2 dan 4 buah pondsi yang diikat menjadi satu

Adapun tujuan penelitian ini adalah menganalisis penyebab ke tidak efisienan waktu pelaksanaan pekerjaan pondasi gedung kuliah FMIPA UNIMED, sehingga menyebabkan waktu pelaksanaan pekerjaan pondasi menjadi lebih lama dari waktu yang telah direncanakan diawal

\section{METODE PENELITIAN}

Kampus Universitas Negeri Medan berlokasi di Jalan Willem Iskandar, Pasar V Medan Estate, Percut Sei Tuan, Deli Serdang dekat perbatasan Kota Medan serta mempunyai luasan tanah $\pm 495.000 \mathrm{M} 2$

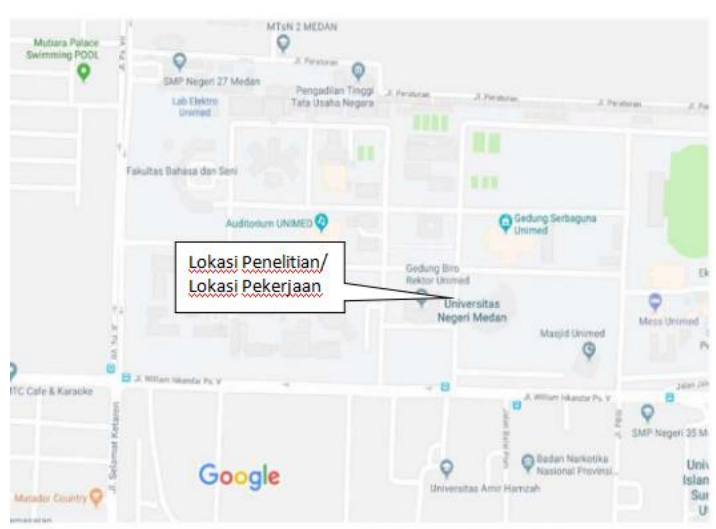

Gambar 2. Peta lokasi Universitas Negeri Medan (UNIMED)

Penelitian ini merupakan sebuah penelitian deskriptif dengan pendekatan kualitatif. [4] mendefinisikan penelitian kualitatif sebagai prosedur penelitian yang menghasilkan data deskriptif berupa kata-kata tertulis atau lisan dari orang-orang dan perilaku yang diamati dari fenomena yang terjadi. Lebih lanjut [4] mengemukakan bahwa penelitian deskriptif menekankan pada data berupa kata-kata, gambar, dan bukan angka-angka yang disebabkan oleh adanya penerapan metode kualitatif. Selain itu, semua yang dikumpulkan berkemungkinan menjadi kunci terhadap apa yang sudah diteliti. Pengambilan sampel atau sumber data pada penelitian ini dilakukan secara puposive dan untuk ukuran sampel tersebut ditentukan secara snowball, teknik pengumpulan dengan gabungan (triangulasi), analisa data bersifat kualitatif dan hasil penelitian menekankan makna generalisasi. Hasil dari penelitian ini hanya mendeskripsikan wawancara-wawancara mendalam terhadap subjek penelitian sehingga dapat memberikan gambaran yang jelas mengenai pemahaman work schedule (jadwal pelaksanaan pekerjaan) serta network planning (NWP) pada Pembangunan Gedung Kuliah UNIMED.

Pada prosedur penelitian ini digunakan metode orientasi dan observasi. Orientasi dilaksanakan sebelum diadakan perbaikan (reschedue), sedangkan observasi dilaksanakan pada waktu berlangsungnya pelaksanaan dilapangan. Data yang diperoleh adalah data kualitatif dan data kuantitatif.

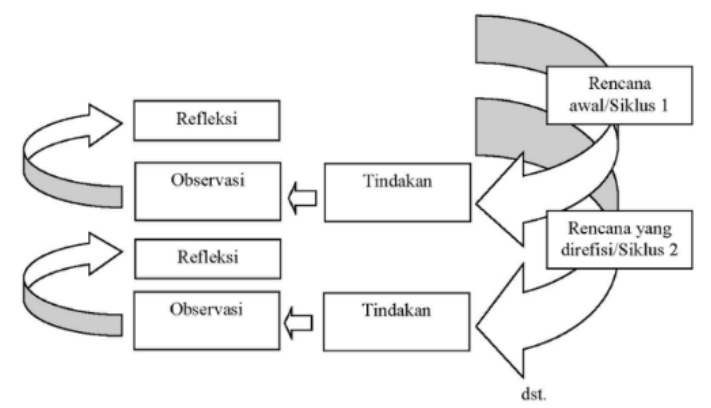

. Gambar 3. Langkah-langkah Penelitian

Adapun skema/proses penelitian ini dapat dilihat dalam bentuk diagram alir sebagai berikut: 


\section{JURNAL ILMIAH TEKNIK MESIN, INDUSTRI, ELEKTRO DAN SIPIL}

Analisis reschedule terhadap pelaksanaan pekerjaan struktur bawah gedung fmipa UNIMED

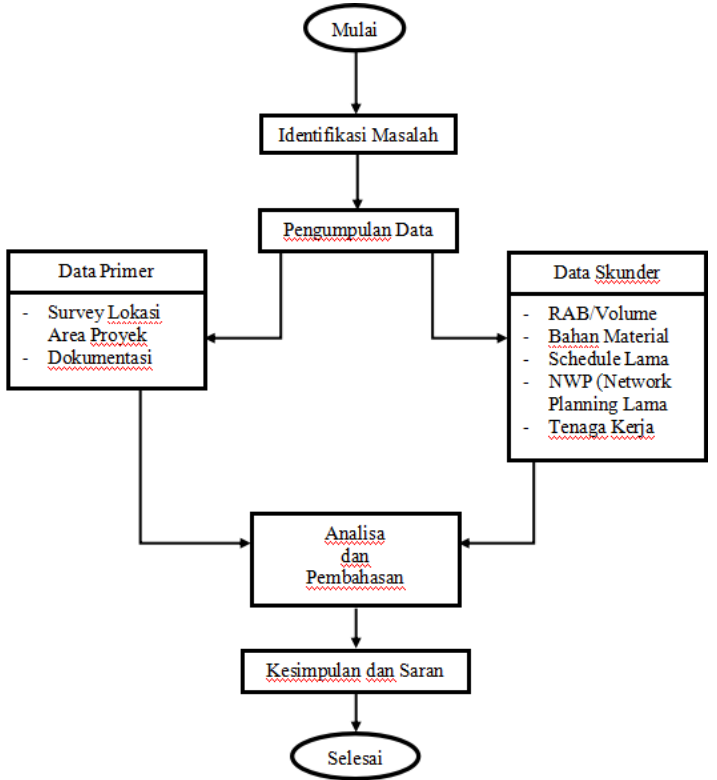

Gambar 4. Flowchat Penelitian

\section{HASIL DAN PEMBAHASAN}

Dalam pelaksanaan pembangunan gedung UNIMED, faktor material sangat berperan penting, karena hal ini menyangkut kelancaran pekerjaan. Bahan material untuk pekerjaan struktur pondasi yaitu beton yang diproduksi oleh readymix. Adapun NWP (Network Planning) lama yang didapat di lapangan dalam Time schedule lama Proyek pekerjaan pondasi Gedung dalam bentuk Network Planning (NWP) adalah sebagai berikut:

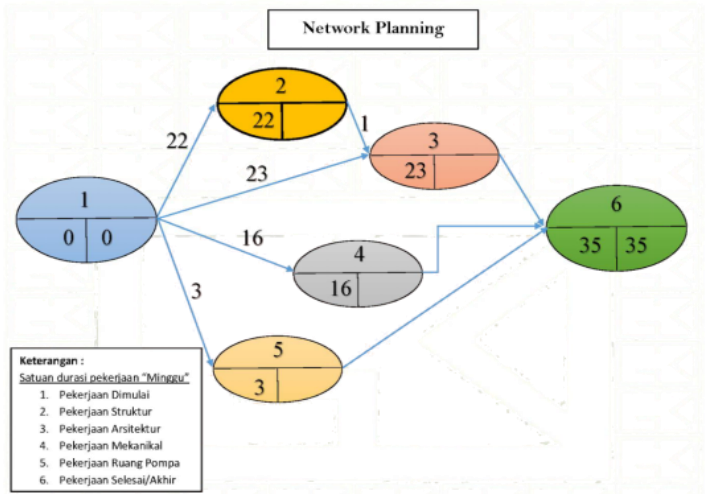

Gambar 5. Network Planning (lama)

1. Analisa Durasi Pelaksanaan

Waktu pelaksanaan pekerjaan struktur bawah awalnya adalah 8 minggu, yaitu pekerjaan pondasi 5 minggu, dan pekerjaan pile cap memakan waktu 3 minggu, hingga waktu selurunya adalah 8 minggu. Pada Reschedule waktu pelaksanaan telah direvisi, bahwa durasi pekerjaan Struktur bawah berubah lebih singkat yaitu enam minggu, pekerjaan pondasi lima minggu, sedangkan pekerjaan pile cap selama tiga minggu dapat dimulai saat pekerjaan pondasi sedang berlangsung dan telah mencapai $60 \%$.

Durasi waktu pelaksaan pekerjaan struktur bawah gedung FPMIPA UNIMED awalnya memakan waktu 8 minggu (56 hari), Reschedule terbaru dari analisis dilapangan menjadi 6 minggu (42 hari)

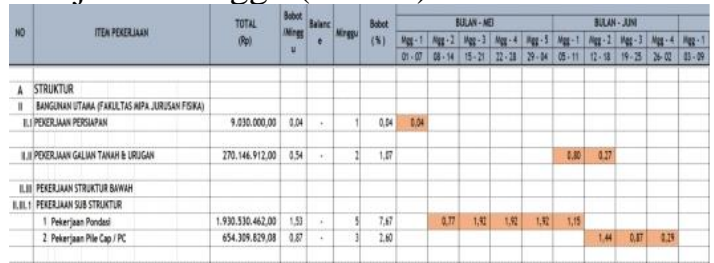

Gambar 6. Schedule Lama

Pile cap dapat dikerjakan saat pekerjaan pondasi telah mencapai $60 \%$, setelah pekerjaan pondasi berpindah ke sektor 2 dengan keseluruhan mobilisasi alat berat dan material. sehingga tidak mengganggu pekerjaan pile cap yang akan dimulai. Pembagian sektor kerja ini sangat penting karena tidak akan saling mengganggu atau menghambat satu sama lain. Mobilisasi alat berat, dan penempatan material memberi ruang gerak untuk pekerjaan pile cap yang akan dimulai saat pekerjaan pondasi disektor 1 selesai.

Adapun Time Schedule yang telah di reschedule dapat dilihat pada tabel beriku

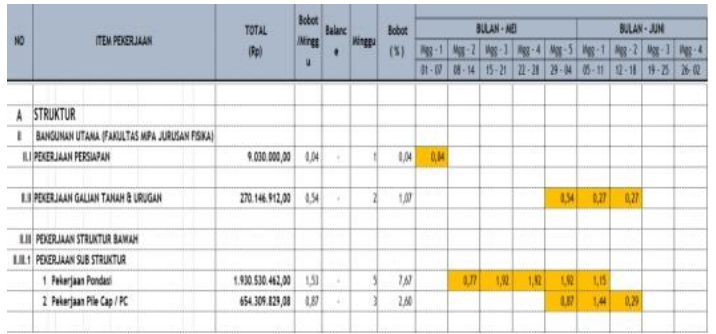

Gambar 7. Schedule Baru (Reschedule)

Secara umum setiap proyek mempunyai durasi waktu dalam pelaksanaan pekerjaan 
yang telah ditentukan oleh pihak pemilik (owner). Durasi waktu yang diberikan oleh pihak pemilik (owner) adalah 35 (tiga puluh lima) minggu atau 245 (dua ratus empat puluh lima) hari kalender untuk pengerjaan secara keseluruhan item pekerjaan mulai dari tahap pendahuluan (start) hingga tahap akhir (finishing).

Untuk durasi waktu pelaksanaan pekerjaan pondasi gedung yaitu 8 (delapan) minggu atau 56 (lima puluh enam) hari kalender jika kita melihat dari schedule lama atau yang telah ada. Mulai dari tahap pendahuluan hingga tahap struktur bawah yaitu pekerjaan pondasi dan pile cap dengan nilai bobot pekerjaan yang berbeda-beda dari nilai total kontrak pekerjaan yaitu \pm Rp.25.179.100.000,- belum termasuk PPN $10 \%$. Untuk lebih rinci bisa kita lihat pada tabel sebagai berikut:

Tabel 1 Rincian Durasi Waktu

\begin{tabular}{lllll}
\hline No. & Jenis Pekerjaan & $\begin{array}{l}\text { Biaya pekerjaan } \\
(\mathrm{Rp})\end{array}$ & $\begin{array}{l}\text { Nilai } \\
\text { Pekerjaan }(\%)\end{array}$ & $\begin{array}{l}\text { Bobot } \\
\text { Wurasi } \\
\text { Waktu } \\
\text { (hari) }\end{array}$ \\
\hline I & Pekerjaan Pendahuluan & $1.475 .906 .229,76$ & 3,08 & 63 \\
\hline A. & Struktur & $9.030 .000,00$ & 0,04 & 7 \\
\hline II.I & Pekerjaan Persiapan & & 1,07 & 14 \\
\hline II.II & Pekerjaan Galian Tanah \& Urugan & $270.146 .912,00$ & \\
\hline II.III & Pekerjaan Struktur Bawah & & & 35 \\
\hline & 1. Pekerjaan Pondasi & $1.930 .530 .462,00$ & 7,67 & 21 \\
\hline & 2. Pekerjaan Pile Cap/PC & $654.309 .829,08$ & 2,60 & \\
\hline & & & 14,464 \\
\hline Jumlah Total & $4.339 .923 .432,84$ & \\
\hline
\end{tabular}




\section{JURNAL ILMIAH TEKNIK MESIN, INDUSTRI, ELEKTRO DAN SIPIL}

Analisis reschedule terhadap pelaksanaan pekerjaan struktur bawah gedung fmipa UNIMED

Pekerjaan pondasi termasuk bagian dari Pekerjaan struktur bawah. Pekerjaan pondasi memakan waktu 35 (enam puluh tiga) hari kalender dengan menghabiskan biaya $\pm \mathrm{Rp}$. 4.339.923.432,--. Seiring berjalan dengan pekerjaan pendahuluan serta pekerjaan persiapan dan yang lainnya. Akan tetapi bila kita melihat dari pekerjaan struktur bawah saja maka hanya menghabiskan biaya $\pm \mathrm{Rp}$. 2,584,840,291,- dengan nilai bobot 10,27\%.

Durasi waktu pelaksaan pembangunan gedung UNIMED awalnya memakan waktu 8 minggu (56 hari), Reschedule terbaru dari analisis di lapangan menjadi 5 minggu (35 hari),

Tabel 2 Perbandingan Waktu Antara Lama dan Baru

\begin{tabular}{|c|c|c|c|}
\hline No & Item & $\begin{array}{l}\text { Time } \\
\text { schedule } \\
\text { lama }\end{array}$ & $\begin{array}{l}\text { Reschedul } \\
e\end{array}$ \\
\hline 1 & $\begin{array}{l}\text { Durasi } \\
\text { pelaks } \\
\text { anaan }\end{array}$ & 8 minggu & 6 minggu \\
\hline 2 & $\begin{array}{l}\text { Sewa } \\
\text { alat } \\
\text { berat }\end{array}$ & Lebih lama & $\begin{array}{l}\text { Lebih } \\
\text { singkat }\end{array}$ \\
\hline 3 & $\begin{array}{l}\text { Biaya } \\
\text { Upah } \\
\text { Man } \\
\text { power }\end{array}$ & $\begin{array}{l}\text { Lebih tinggi } \\
\text { karena lebih } \\
\text { lama } \\
\text { durasinya }\end{array}$ & $\begin{array}{l}\text { Lebih } \\
\text { murah }\end{array}$ \\
\hline 4 & $\begin{array}{l}\text { Efisien } \\
\text { si }\end{array}$ & & $\begin{array}{l}\text { Lebih } \\
\text { efisien }\end{array}$ \\
\hline
\end{tabular}

2. Penjadwalan Ulang (Reschedule)

Reschedule adalah penjadwalan ulang pekerjaan terhadap jadwal pekerjaan sebelumnya dimana dalam penjadwalan ulang ini hanya berfokus pada sumber daya yang akan dijadwalkan selama proses konstruksi baik distribusi jadwal tenaga kerja, material dan peralatan proyek. melakukan reschedule terhadap schedule yang lama serta NWP (Network Planning). Mengingat batasan 8masalah saya sebagai mahasiswa akan membahas pekerjaan struktur bawah saja atau hanya pekerjaan pondasi menghitung ulang durasi waktu pekerjaan atau me-reschedule ulang dari porgram software Microsoft Office (Excel) dan Microsoft Project serta NWP (Network Planning). Time schedule awal (sebelum di reschedule) berkaitan dengan urutan dan prioritas pekerjaan. Pekerjaan pondasi borpile dibagi menjadi dua sektor, dimana sektor pertama membagi lokasi menjadi dua segmen pelaksanaan yaitu :

- Sektor 1 (garis biru) : terdiri dari gugusan pondasi dalam modul yang saling berdekatan dalam denah, yang terdiri dari 44 unit pile.

- Sektor 2 (garis merah): terdiri dari gugusan pondasi dalam modul yang saling berdekatan dalam denah, yang terdiri dari 44 unit pile.

Selanjutnya dapat dilihat pada denah pondasi dibawah ini.

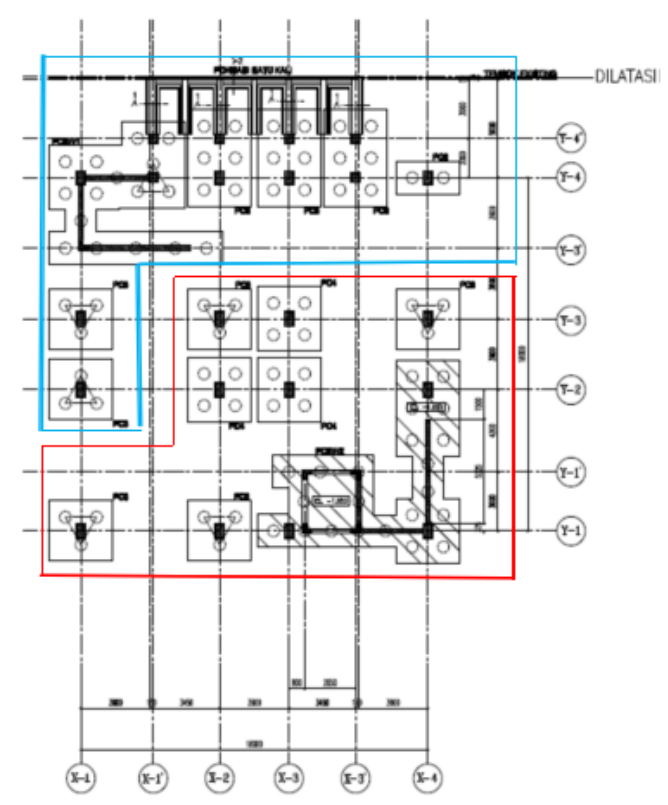

Gambar 8. Schedule Baru (Reschedule)

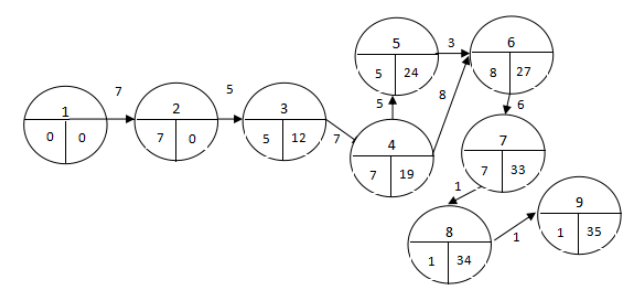

Gambar 9. Networking Baru

\section{KESIMPULAN}

Mekanisme pekerjaan yang tertera pada schedule/jadwal perencanaan/kontraktor tidak seluruhnya bekerja sesuai dengan yang direncanakan, baik itu masalah metode pelaksanaan pekerjaan maupun schedule pekerjaan lainnya.

Time schedule yang telah disusun untuk pelaksanaan proyek ini ternyata tidak 
JURNAL ILMIAH TEKNIK MESIN, INDUSTRI, ELEKTRO DAN SIPIL

Analisis reschedule terhadap pelaksanaan pekerjaan struktur bawah gedung fmipa UNIMED

seluruhnya dapat diikuti. Hal ini dipengaruhi oleh peralatan serta SDM (tenaga kerja), cuaca yang kurang baik berupa hujan, dan juga adanya perubahan gambar rencana serta volume perkerjaan yang tidak sesuai, sehingga perlunya ada perubahan-perubahan yang perlu disetujui atau perlu dirapatkan untuk mendapatkan hasil keputusan yang sesuai dengan kebutuhan proyek tersebut.

Kesiapan intrument kerja, baik dari segi SDM maupun segi akomodasi pada proyek Pembangunan Gedung Gedung FMIPA UNIMED haruslah siap kerja over time (kerja lembur) agar efektivitas dan efisiensi serta progres kerja dapat dicapai sesuai waktu yang telah ditentukan oleh pengguna jasa (owner).

\section{DAFTAR PUSTAKA}

[1] M. Tanjung, "Fungsi Organisasi dalam Manajemen Proyek," Jurnal Mantik Penusa, vol. 1, no. 1, pp. 22-26, 2017.

[2] I. M. R. Muhammad Imam Munandar, "Manajemen Konstruksi Pembangunan Guest House Sutan Raja Kota Cirebon," Jurnal Konstruksi UNSWAGATI Cirebon, vol. VI, no. 2, pp. 165-177, 2017.

[3] S. Yoseph Enrico, "Manajemen Konstruksi pada proyek pembangunan Jembatan untuk akses ke lokasi PT. Pertamina MB-04," Jurnal Konstruksi, vol. VIII, no. 1, pp. 472479, 2019.

[4] A. A. H. Slamet Riyanto, Metode Riset, Penelitian Kuantitatif, Yogyakarta: Deepublish, 2019. 